\title{
Characterization of virulent Listeria monocytogenes isolates recovered from ready-to-eat meat products and consumers in Cairo, Egypt
}

\author{
Maysa A. I. Awadallah¹, and Iman I. A. Suelam²
}

1. Department of Zoonoses, Faculty of Veterinary Medicine, Zagazig University, Zagazig, Egypt; 2. Veterinary Hospital, Faculty of Veterinary Medicine, Zagazig University, Zagazig, Egypt.

Corresponding author: Maysa A. I. Awadallah, e-mail: maysavet@hotmail.com, IIAS: Dakahlia2000@yahoo.com Received: 30-06-2014, Revised: 01-09-2014, Accepted: 05-09-2014, Published online: 09-10-2014

doi: 10.14202/vetworld.2014.788-793. How to cite this article: Awadallah MAI, Suelam IIA (2014) Characterization of virulent Listeria monocytogenes isolates recovered from ready-to-eat meat products and consumers in Cairo, Egypt, Veterinary World 7(10): 788-793.

\begin{abstract}
Aim: This study aimed to investigate the occurrence of some virulence genes distributed in Listeria monocytogenes isolated from ready-to-eat (RTE) meat products and consumers in Cairo province, Egypt.

Materials and Methods: A total of 120 beef luncheon, chicken luncheon and frankfurter beef (40 samples, each) were collected from 10 different local shops situated in Al-salam city, Cairo province, Egypt. Stool samples were collected from 40 people who had the habit of consuming RTE meat. The suspected L. monocytogenes isolates were subjected to a multiplex polymerase chain reaction (PCR) for rapid speciation and virulence determination using primers specific for inIA, inIC, and inIJ genes.

Results: Culture examination of all samples on Oxford media revealed presence of colonies characteristic to $L$. monocytogenes in 6 beef luncheon (15\%), 4 chicken luncheon (10\%), 1 frankfurter beef (2.5\%) and 1 human stool (2.5\%) samples. Species identity of $L$. monocytogenes was verified through the amplification of a 800 bp fragment with inIA primers in 2 out of 6 culture isolates from beef luncheon (5\%), and 1 out 4 culture isolates from chicken luncheon (2.5\%) samples. Statistical analysis revealed no significant difference between the occurrence of $L$. monocytogenes in different food samples examined (p>0.05). The virulence of these strains was ascertained by the presence of $517 \mathrm{bp}$ and $238 \mathrm{bp}$ fragments of inIC and inIJ genes, respectively in the isolates that contained the $800 \mathrm{bp}$ fragment. The culture isolates obtained from one frankfurter beef sample, and one human stool sample were found negative by multiplex PCR for the presence of L. monocytogenes and its virulence specific genes.
\end{abstract}

Conclusion: It could be concluded that L. monocytogenes are circulating in beef and chicken luncheon sold in Cairo, Egypt. Multiplex PCR is reliable for confirmation of L. monocytogenes. This study suggests the implementation of hygienic measures at all levels from production to consumption in order to improve food safety. Furthermore, authors recommended consumption of beef frankfurter or any RTE meat sold in their original intact packing due to low level of contamination.

Keywords: Listeria monocytogenes,, consumers, ready-to-eat meat, speciation and virulence determination.

\section{Introduction}

Listeriosis has now been recognized as an emerging food borne zoonoses [1]. Listeria monocytogenes has been recognized as an important opportunistic human pathogen since 1929 and as food borne pathogen since 1981 [2]. Ready-to-eat (RTE) meat products are, usually, cooked during manufacture and consumed without further heating. Hence, they present high risk to the consumers due to possible cross contamination with food borne pathogens and further growth of such pathogens [3]. The extended distribution throughout the food processing environment and asymptomatic human carriers [4] and the psychrotrophic character of Listeria species appear to be the main causes of the prevalence in different kinds of refrigerated RTE meat products and contamination could occur either pre- or post-processing [5].

Copyright: The authors. This article is an open access article licensed under the terms of the Creative Commons Attributin License (http:// creative commons.org/licenses/by/2.0) which permits unrestricted use, distribution and reproduction in any medium, provided the work is properly cited.
Of the 20 RTE food categories evaluated by the Food and Drug Administration and the Food Safety and Inspection Service, deli meats were classified in the very high risk category to be the principal potential source of L. monocytogenes [6]. In general, consumption of food contaminated with $L$. monocytogenes may cause listeriosis which may result in serious human illness with symptoms of septicemia, meningitis, encephalitis and gastroenteritis particularly in children, the elderly and immunosuppressed individuals. It may also cause miscarriage in pregnant women [7]. $L$. monocytogenes had the second highest fatality rate (20\%) and the highest hospitalization rate (90\%) in virulence [8]. Multistate outbreaks of food borne listeriosis were recorded [9].

Given the close morphological and biochemical resemblances of $L$. monocytogenes to other Listeria species, and the non-specific clinical manifestations of listeriosis [10], the availability of rapid, specific and sensitive diagnostic tests capable of distinguishing L. monocytogenes from other Listeria species is essential for the effective control of the disease. 
Internalin genes (InlA, InlJ and InlC) are a panel of virulence-specific genes that involved directly in L. monocytogenes passage through the intestinal barriers as well as involvement in the subsequent stages of infection [11]. InlA was intended for species- specific recognition while InlJ and InlC were designed for virulence determination of $L$. monocytogenes. Polymerase chain reaction (PCR) is deemed to be more reliable than conventional methods of identification [12].

The increase of RTE food consumption due to changes in the lifestyle and the ability of $L$. monocytogenes to attach to different surfaces forming biofilms and consequently its persistence in food environment necessitate periodically repeated surveys for determining the prevalence and the distribution of some virulence genes in $L$. monocytogenes isolated from RTE food and consumers.

\section{Materials and Methods}

\section{Ethical approval}

Human samples were obtained after having an informed consent.

\section{Sampling}

The samples used in this study were:

RTE meats that did not require any further cooking prior to consumption. The categories of RTE meats purchased were beef luncheon, chicken luncheon and frankfurter beef (40 samples, each). Beef luncheon, chicken luncheon were repacked at the markets and local shops. However, the frankfurter beef samples were purchased in their original intact packing. Immediately after purchase, the samples were transferred on ice to the laboratory and stored at $4^{\circ} \mathrm{C}$ until analysis.

Stool samples: After contacting of about 100 people, a total of 40 persons of different age groups and have the habit of eating RTE meat of the same categories examined, were investigated for the presence of $L$. monocytogenes in their stool. The forty persons were apparently healthy at the time of stool collection; however, eight of them had got a transient diarrhea within 1-2 months before being investigated. Stool cups were distributed 1 day before collection. Stool samples were transported to the laboratory on ice and stored at $4^{\circ} \mathrm{C}$ until analysis.

\section{I solation and identification of L. monocytogenes}

RTE meat: The packages containing RTE meats were disinfected at the incision site by swabbing with $70 \%$ ethanol [8]. Analytical portion (25 g) was aseptically weighed using a sterile spatula and blended for 1 min with $225 \mathrm{ml}$ of buffered peptone water (BPW, Oxoid, CM509). The homogenate was transferred to a sterile bottle jar and was incubated at $30^{\circ} \mathrm{C}$ for $24 \mathrm{~h}$. $1 \mathrm{ml}$ of the incubated homogenate was added to $9 \mathrm{ml}$ of Listeria selective broth (Himedia, 569-500G) and further incubated for $48 \mathrm{~h}$ at $30^{\circ} \mathrm{C}$. Thereafter, the homogenate was streaked onto the Oxford agar plates
(Himedia, MV1145-500G with Listeria Oxford supplement Himedia, FD071), incubated for $48 \mathrm{~h}$ at $37^{\circ} \mathrm{C}$. Grey colonies surrounded by black zone (suspected L. monocytogenes) were picked up and purified on nutrient agar plates.

Stool samples: A swab taken from each stool sample using a sterile swab was immersed in sterile BPW tubes under aseptic condition. The tubes were labeled with respect to name, age, sex, and date of collection. The remaining steps were carried out as those applied for RTE meat samples.

Multiplex PCR for speciation and virulence determination of $L$. monocytogenes culture isolates

The $L$. monocytogenes culture isolates obtained from RTE and human stool samples were subjected to a multiplex PCR specific for L. monocytogenes speciation and virulence determination.

Genomic DNA extraction: For each suspected L. monocytogenes isolate, a $10 \mathrm{ml}$ culture was grown in Tryptose soya broth, and $1 \mathrm{ml}$ of cells was pelleted by centrifugation at $10,000 \mathrm{rpm}$ for $30 \mathrm{~s}$. The cell pellets were re-suspended in $200 \mu$ physiological saline. The re-suspended cells were re-centrifuged at $10,000 \mathrm{rpm}$ for $30 \mathrm{~s}$. The cell pellets were then used for DNA extraction using bacterial DNA extraction kit (spin-column) (BioTeke Corporation, DP2001) as recommended by the manufacturers. Protocol for Gram-positive bacteria, cellular lyses, was carried out by enzymatic fragment with lysozyme. DNA samples were stored at $-20^{\circ} \mathrm{C}$ until used.

Primers used: The oligonucleotide primers targeting L. monocytogenes internalin genes inIA (intended for species-specific recognition) and the inIC and inIJ (intended for virulence determination of $L$. monocytogenes) as mentioned by Liu et al., [13] were used in this study. Primer sequences used are listed in Table-1.

\section{Multiplex PCR steps for amplification of the target genes}

Multiplex PCR was conducted in primus thermocycler (MWG-Biotech) in a volume of $25 \mu \mathrm{l}$ containing $0.8 \mathrm{U}$ Taq DNA polymerase (Fisher Scientific, Houston, TX), $\times 1$ PCR buffer, $200 \mu \mathrm{M}$ dNTPs and $10 \mathrm{ng}$ each Listeria DNA, together with $40 \mathrm{pmol}$ each inIA, 30 pmol each inIC and 20 pmol each inIJ primers. Reaction mixture with no DNA template and known L. monocytogenes isolate were incorporated as negative and positive control, respectively in each run. The cycling program consisted of $\times 194^{\circ} \mathrm{C}$ for $2 \mathrm{~min}$; $\times 3094^{\circ} \mathrm{C}$ for $20 \mathrm{~s}, 55^{\circ} \mathrm{C}$ for $20 \mathrm{~s}$, and $72^{\circ} \mathrm{C}$ for $50 \mathrm{~s}$; and $\times 172^{\circ} \mathrm{C}$ for 2 min [13].

Gel electrophoresis: All amplification products were resolved in $1.25 \%$ agarose gel, stained with ethidium bromide, detected under Ultraviolet Transilluminator (Spectroline). The 100 bp ladder was used as a molecular size marker.

\section{Results}

Table-2 shows that out of 120 RTE meat samples examined by culture, 11 samples (9.16\%) were 
Table-1: Oligonucleotide sequences of the primers used in multiplex PCR assay for L. monocytogenes.

\begin{tabular}{lclcr}
\hline Target gene & Coding sequences & Primer sequences (5-3) & Nucleotide positions & Expected PCR product (bp) \\
\hline inl A & $94534-96936$ & ACGAGTAACGGGACAAATGC & $94612-94631$ & 800 \\
\multirow{2}{*}{ inlC } & CCCGACAGTGGTGCTAGTT & $95411-95392$ & 517 \\
\multirow{2}{*}{ inlJ } & $107200-108090$ & AATTCCCACAGGACACAACC & $107306-107325$ & 238 \\
& & CGGGAATGCAATTTCACTA & $107822-107802$ & $188989-189009$ \\
\end{tabular}

$\mathrm{PCR}=$ Polymerase chain reaction, L. monocytogenes=Listeria monocytogenes

Table-2: Suspected L. monocytogenes isolates detected in RTE meat products and human stool samples.

\begin{tabular}{lccc}
\hline Source & $\begin{array}{c}\text { Number of } \\
\text { analyzed } \\
\text { samples }\end{array}$ & $\begin{array}{c}\text { Number } \\
\text { of positive }\end{array}$ & $\begin{array}{c}\% \text { of } \\
\text { positive }\end{array}$ \\
\hline Beef luncheon & 40 & 6 & 15 \\
Chicken luncheon & 40 & 4 & 10 \\
Frankfurter beef & 40 & 1 & 2.5 \\
Total & 120 & 11 & 9.16 \\
Human stool & 40 & 1 & 2.5 \\
\hline
\end{tabular}

RTE=Ready-to-eat, L. monocytogenes=Listeria

monocytogenes

positive for the presence of suspected L. monocytogenes isolates. These 11 isolates were; 6 from beef luncheon (15\%), 4 from chicken luncheon (10\%), and 1 from frankfurter beef (2.5\%). Suspected L. monocytogenes isolate was detected in only one (2.5\%) stool sample out of the 40 human stool samples. Statistical analysis revealed no significant difference between the occurrence of $L$. monocytogenes in different food samples examined ( $\mathrm{p}>0.05)$.

Table- 3 and Figure- 1 show the results of multiplex PCR for speciation and virulence determination of the suspected L. monocytogenes isolates obtained from the 11 RTE meat samples and one human stool sample. Species specific gene (inIA, 800 bp) of $L$. monocytogenes and the virulence genes (inIC and inIJ that have molecular weight of 517 and 238, respectively) were detected in two suspected $L$. monocytogenes isolates out of six from beef luncheon (5\%) and one isolate out of four from chicken luncheon (2.5\%). On the other hand, suspected L. monocytogenes isolates from one frankfurter beef, and one human stool were negative by multiplex PCR $(0 \%)$. All samples positive for inIA (Species identity gene) were also positive for the presence of inIC and inIJ (virulence specific genes).

\section{Discussion}

The primary vehicle for Listeria infection is food. Normally, meat and meat products, vegetables, fish, dairy products, minimal processed food and RTE foods are potential sources of transmission [14]. The overall prevalence of $L$. monocytogenes in all RTE meat products examined $(9.16 \%)$ in the current study agreed with previous studies showing that prevalence of $L$. monocytogenes in RTE meat products may vary from 0 to $72 \%$, with different level of CFU per gram up on expiry of the shelf life [15]. Lower prevalence of

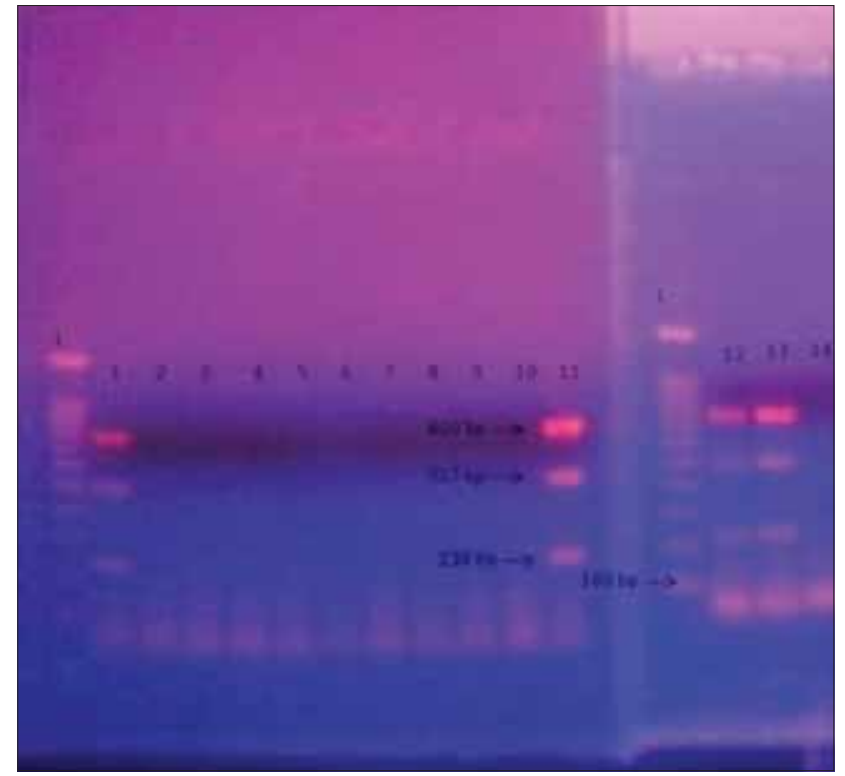

Figure-1: Agarose gel electrophoresis of multiplex polymerase chain reaction products obtained from representative suspected L. monocytogenes culture isolates. Lanes (source): L (100 bp ladder); 1 (Positive control); 2 (HS); 3, 9, 11, 4 (CL); 5, 10, 7, 8, 12, 13 (BL); $10(\mathrm{CL}) ; 6$ (FB); 14 (Negative control). HS: Human stool, $\mathrm{CL}$ : Chicken luncheon, BL: Beef luncheon, FB: Frankfurter beef.

3.4, 1.2 and $1.5 \%$ in meat product samples were previously reported in Czech Republic [16], Sweden [17], and Jordon [18], respectively.

L. monocytogenes was previously detected in 12 and 17\% of beef luncheon and chicken luncheon examined in Egypt [19]. They attributed the higher prevalence of $L$. monocytogenes to the nature of samples they examined. Their samples were collected from street vendors lacking refrigeration facilities, sources of running water, personal hygiene and public toilets. A lower prevalence of $L$. monocytogenes in beef luncheon was previously reported by Gombas et al., [20]. A higher prevalence (11\%) of L. monocytogenes was previously recorded in frankfurter beef samples in Sweden [21].

In the current study, the prevalence of suspected L. monocytogenes was higher in RTE meat samples repacked at local shops (beef and chicken luncheon) than those purchased in their original intact packing (frankfurter beef). These results agreed with Gelbicova and Karpiskova, [16] who found $83 \%$ of the positive samples originated from sliced products. They stated that the undesirable bacterial contamination of meat 
Table-3: Multiplex PCR for speciation and virulence determination of 12 suspected L. monocytogenes isolates using internalin genes primers (inl A, inlC, and inlJ).

\begin{tabular}{lcccc}
\hline Source & $\begin{array}{c}\text { Number } \\
\text { of isolates }\end{array}$ & \multicolumn{2}{c}{ Multiplex PCR positive isolates(\%) } \\
\cline { 3 - 5 } & & $\begin{array}{c}\text { Isolates containing } \\
\text { inI A ( } \mathbf{8 0 0} \mathbf{~ b p )}\end{array}$ & $\begin{array}{c}\text { I solates containing } \\
\text { inl C (517 bp) }\end{array}$ & $\begin{array}{c}\text { I solates containing } \\
\text { inI J (238 bp) }\end{array}$ \\
\hline Beef luncheon & 6 & $2(5)^{\text {a }}$ & $2(5)$ & $2(5)$ \\
Chicken luncheon & 4 & $1(2.5)$ & $1(2.5)$ & $1(2.5)$ \\
Frankfurter beef & 1 & $0(0)$ & $0(0)$ & $0(0)$ \\
Total & 11 & $3(2.5)$ & $3(2.5)$ & $3(2.5)$ \\
Human stool & 1 & $0(0)$ & $0(0)$ & $0(0)$
\end{tabular}

aThe percentage of samples positive by PCR to total examined. PCR=Polymerase chain reaction,

L. monocytogenes=Listeria monocytogenes

products could occur either directly in the manufacturing process or as a result of subsequent handling, storage or distribution. Moreover, Garrido et al., [22] in Spain reported higher incidence in in-store-packaged products $(8.5 \%)$ as compared to products packaged by manufacturer (2.7\%). They suggested that the slicing equipment could be a source for the pathogen dissemination.

In healthy adults, consumption of L. monocytogenes contaminated food usually causes only a short period of shedding without any illness; however, in the high risk groups (pregnant, newborns, the elderly, and adults with weakened immune system) oral exposure can lead to listeriosis. Asymptomatic fecal carriage occurs in approximately $3 \%$ of healthy human, with point prevalence increasing to $26 \%$ in high-risk groups [23]. L. monocytogenes was found to be positive in 1.15\% (10 out of 868) and 2\% (1/50) of stool samples in Austria [24] and Egypt [25]. Grif et al., [24] attributed the lower isolation rate of $L$. monocytogenes from human stool samples to the secretion of gastric acid that provides an important protective factor against the passage of potentially pathogenic organisms. A drastically increased prevalence of L. monocytogenes in the stool of patients receiving long-term $\mathrm{H} 2$ blockers was shown compared to the prevalence in patients with normal gastric secretion [26].

The standard microbiological methods for identification of Listeria spp. are laborious, and time-consuming, requiring a minimum of 5 days to recognize Listeria spp and about 10 days to identify L. monocytogenes by confirmation test [27]. The wide application of nucleic acid amplification techniques and the increasing industrial interest toward rapid and sensitive method has led to the development and application of PCR based methods for the detection of microbial pathogen in food [28]. Typing of L. monocytogenes is necessary when performing epidemiological investigations [29].

Species specific gene (inIA, 800 bp) of L. monocytogenes and the virulence genes (inIC and inIJ that have molecular weight of 517 and 238, respectively) were detected in two suspected $L$. monocytogenes isolates out of six from beef luncheon and one isolate out of four from chicken luncheon obtained during this study. On the other hand, suspected $L$. monocytogenes isolates obtained from one frankfurter beef, and one human stool were found to be negative by multiplex PCR. As it was illustrated in Tables-2 and 3, there were a difference between the prevalence of L. monocytogenes in RTE meat products and human stool depending on the technique used for detection. Difference in the prevalence rate of $L$. monocytogenes in the examined RTE meat using bacteriological examination compared to PCR technique were previously recorded in USA [11] and Egypt [30]. Similar difference was recorded in the examined human stool samples. Abdel-Malek et al., [30] detected suspected L. monocytogenes isolates in two human stool samples out of 28 examined by culture. Upon confirmation using PCR technique using Prf A (transcriptional activator of the virulence factor gene of), the two isolates were not $L$. monocytogenes but were found to be L. seeligeri and L. murray (1 isolate, each). L. monocytogenes isolated from raw meat samples were positive to some virulence genes such as actA, flaA, hlyA, iap, inlA and inlB [31]. The difference in the results between bacteriological examination and PCR technique may be due to false positive results with bacteriological examination. Some bacteria have cultural morphology similar to that of $L$. monocytogenes. Staphylococcus aureus, a Listeria like organism, and Enterobacter faecium can cause false positive results in conventional test, and occasionally showed slight discoloration of the selective broth and similar colonies on Oxford agar [11].

The results of this study reveal a potential public health hazard linked to the consumption of RTE meat products and highlights the need for more effective and efficient processing and storage to keep such products safe for consumption. The multiplex PCR used in this study could be a sensitive and rapid procedure for the specific detection of the virulent strain of L. monocytogenes. To our knowledge this is the first attempt in Egypt using multiplex PCR to confirm the prevalence of a virulent strain of $L$. monocytogenes in RTE foods. This assay could be of great importance in the epidemiological investigations in the case of food borne illnesses and trace back for the source of contamination. The data suggest a need to improve consumer education regarding food processing and storage practices in Egypt. The importance of storing 
RTE meat at low temperatures $\left(\leq 4^{\circ} \mathrm{C}\right)$ and taking into account the maximum storage time before consumption should be emphasized in consumer education.

\section{Conclusion}

It could be concluded that $L$. monocytogenes are circulating in beef and chicken luncheon sold in Cairo, Egypt. Multiplex PCR is reliable for confirmation of $L$. monocytogenes. This study suggests the implementation of hygienic measures at all levels from production to consumption in order to improve food safety. Furthermore, authors recommended consumption of beef frankfurter or any RTE meat sold in their original intact packing due to low level of contamination.

\section{Authors' Contribution}

AMAI: Designed the study and collected RTE meat product samples \& human stools, shared in the practical part in the laboratory. SIIA shared in the practical part in the laboratory and collection of papers. AMAI drafted and revised the manuscript. Both authors read and approved the final manuscript.

\section{Acknowledgments}

The authors are thankful to Mohamed Afifi for his valuable assistance in performing the statistical analysis. This work was done on authors' expense without funding from any organization. Necessary facilities of department of Zoonoses, Faculty of Veterinary Medicine, Zagazig University were used.

\section{Competing I nterests}

The authors declare that they have no competing of interests.

\section{References}

1. Dhama, K., Verma, A.K., Rajagunalan, S., Kumar, A., Tiwari, R., Chakraborty, S. and Kumar, R. (2013) Listeria monocytogenes infection in poultry and its public health importance with special reference to food borne zoonoses, Pak. J. Biol. Sci., 16: 301-8.

2. Jeyasekaran, G., Karunasagar, I. and Karunasagar, I. (1996) Incidence of Listeria spp. In tropical fish. Int. J. Food Microbiol., 31: 333-340.

3. Goulet, V., Hedberg, C., Le Monnier, A. and De Valk, H. (2008) Increasing incidence of listeriosis in France and other European countries. Emerg. Infect. Dis., 14: 734-740.

4. Wagner, M., Melzner, D., Bago, Z., Winter, P., Egerbacher, M., Schilcher, F., Zangana, A. and Schoder, D. (2005) Outbreak of listeriosis in sheep: Evaluation from possible contamination routes from feed to raw produce and humans. J. Vet. Med., 52: 278-283.

5. Lianou, A. and Sofos, J.N. (2007) A review of the incidence and transmission of Listeria monocytogenes in ready-to-eat products in retail and food service environment. J. Food Prot., 70: 2172-2198.

6. FAO/WHO. (2010) Risk assessment of Listeria monocytogenes in ready-to-eat food, 2004. Available from: http:// www.fao.org/docrep/010/y5394e/y5394e00.htm. [Last accessed on 2010 May 31].

7. Blum-Menezes, D., Deliberalli, I., Bittencourt, N.C., do Couto, C.A.T., Barbosa, L.N., dos Santos, A.M. and Pinto, G.G. (2013) Listeriosis in the far South of Brazil:
Neglected infection. Rev. Soc. Bras. Med. Trop., 46: 381-383.

8. Swaminathan, B. (2001) Listeria monocytogenes. In: Doyle, M.P., Beuchat, L.R. and Montville, TJ. editors. Food Microbiology. Food Fundamentals and Frontiers. American Society for Microbiology, Washington D.C., USA. p383-409.

9. Gottlieb, S.L., Newbern, E.C., Griffin, P.M., Graves, L.M., Hoekstra, R.M., Baker, N.L., Hunter, S.B., Holt K.G., Ramsey, F., Head, M., Levine, P., Johnson, G., Schoonmaker-Bopp, D., Reddy, V., Kornstein, L., Gerwel, M., Nsubuga, J., Edwards, L., Stonecipher S., Hurd, S., Austin, D., Jefferson, M.A., Young, S.D., Hise, K., Chernak, E.D. and Sobel, J. (2006) Multistate outbreak of listeriosis linked to turkey deli meat and subsequent changes in US regulatory policy, Clin. Infect. Dis., 42: 29-36.

10. Vazquez-Boland, J.A., Kuhn, M., Berche, P., Chakraborty, T., Dominguez-Bernal, G., Goebel, W., Gonzalez-Zorn, B., Wehlan, J. and Kreft, J. (2001) Listeria pathogenesis and molecular virulence determinants. Clin. Infect. Dis., 42: 29-36.

11. Peng, H. and Shelef, L.A. (2001) Automated simultaneous detection of low level of Listeria and salmonella in food. Int. J. Food Microbiol., 63: 225-233.

12. Shalaby, M.A., Mohamed, M.S., Mansour, M.A. and AbdEl-Haffiz, A.S. (2011) Comparison of polymerase chain reaction and conventional methods for diagnosis of Listeria monocytogenes isolated from different clinical specimens and food stuffs. Clin. Lab., 57: 919-24.

13. Liu, D., Lawrence, M.L. Austin, F.W. and Ainsworth, A.J. (2007) A multiplex PCR for species and virulence-specific determination of Listeria monocytogenes. J. Microbiol. Methods., 71: 133-140.

14. Arun, KB. (2008) Food-Borne Microbial Pathogen Mechanisms and Pathogenesis. 165-182.

15. Farber, J.M., Pagotto, M. and Scherf, C. (2007) Incidence and behavior of $L$. monocytogenes in meat products. In: Ryser, E.T., Marth, E.H, editors. Listeria Listeriosis and Food Safety. CRC Press Taylor and Francis Group, New York. p503-570.

16. Gelbicova, T. and Karpiskova, R. (2009) Occurrence and characteristics of $L$. monocytogenes in ready-to-eat food from retail market in the Czech Republic. Czech J. Food Sci., 27(2): S2-3-S2-7.

17. Lambertz, S.T., Nilsson, C., Bradenmark, A., Sylven, S., Johansson, A., Jansson, L.M. and Lindblad, M. (2012) Prevalence and level of $L$. monocytogenes in ready-to-eat food in Sweden. Int. J. Food Microbiol., 60: 24-31.

18. Osaili, T.M., Al-Nabulsi, A.A., Shaker, R.R., Jaradat, Z.W., Taha, M., Al-Kherasha, M., Meherat, M. and Holley, R. (2014) Prevalence of Salmonella serovars, Listeria monocytogenes, and Escherichia coli O157:H7 in mediterranean ready-to-eat meat products in Jordan. J. Food Prot., 77:106-11.

19. El-shenawy, M.A., El-shenawy, M.A., Manes, J. and Soriano, J.M. (2011) Listeria species in street vended readyto-eat food. Interdiscip. Perspect. Infect Dis, 968031: 6.

20. Gombas, D.E., Chen, Y., Clavero, R.S. and Virginia, N. (2003) Survey of L. monocytogenes in ready-to-eat food. J. Food Prot., 66: 556-569.

21. Johansson, T. (1998) Enhanced detection and enumeration of $L$. monocytogenes from foodstuffs and food processing environments. Int. J. Food Microbiol., 40: 77-85.

22. Garrido, V., Vitas, A.I. and Garcia-Jalon, I. (2009) Survey of L. monocytogenes in ready-to-eat meat products: prevalence by brand and retail establishments for exposure assessment of listeriosis in Northern Spain. Food control., 20: 986-991.

23. Grif, K., Hein, I., Wagner, M., Brandl, E., Mpamuge, O., Mclauchlin, J., Dierich, M.P. and Allerberger, F. (2001) Prevalence and characterization of Listeria monocytogenes in faeces of healthy Austrians. Wien. Klin. Wochenschr., 113: 737-742.

24. Grif, K., Patscheider, G., Dierich, M.P. and Allerberger, F. 
(2003) Incidence of fecal carriage of L. monocytogenes in three healthy volunteers: a one-year prospective stool survey. Europ. J. Clin. Microbiol. Infect. Dis., 22: 16-20.

25. Ahmed, H.A., Hussein, M.A. and El-Ashram, A.M.M. (2013) Seafood a potential source of some zoonotic bacteria in Zagazig, egypt, with the molecular detection of Listeria monocytogenes virulence genes. Vet. Italiana., 49: 299-308.

26. Cobb, C.A., Curtis, GD., Bansi, D.S., Slade, E., Mehal, W., Mitchell, R.G. and Chapman, R.W. (1996) Increased prevalence of $L$. monocytogenes in the faeces of patients receiving long-term H2 antagonistis. Eur. J. Gastroventrol. Hepatol., 8: 1071-1074.

27. Amagliani, G., Giammarini, C., Omiccioli, E., Brandi, G. and Magani, M. (2007) Detection of L. monocytogenes using commercial PCR Kit and different DNA extraction methods. Food Control., 18: 1137-112.

28. Germini, A., Masola, A., Carnevali, P. and Marchelli, R. (2009) Simultaneous detection of E. coli O157:H7,
Salmonella species and $L$. monocytogenes by multiplex PCR. Food Control., 20(8): 733-738.

29. Kusar, D., Kavalic, M., Ocepek, M. and Zdovc, I. (2013) Report on overcoming the poor quality of ApaI pulsotypes with a short review on PFGE for Listeria monocytogenes. Polish. J. Microbiol., 62: 307-309.

30. Abdel-Malek, A.M., Sohaila, F.H.A., Hassanein, R., AbdelAzeem, M., Mohamad and El-Sayh, K.I. (2010) Occurrence of Listeria species in meat chicken products and human stools in Assiut city, Egypt with PCR use for rapid identification of L. monocytogenes. Vet. World., 3(8): 335-359.

31. Indrawattana, N., Nibaddhasobon, T., Sookrung, N., Chongsa-nguan, M., Tungtrongchitr, A., Makino, S., Tungyong, W. and Chaicumpa, W. (2011) Prevalence of Listeria monocytogenes in Raw Meats Marketed in Bangkok and Characterization of the Isolates by Phenotypic and Molecular Methods., J Health Popul Nutr. Feb 2011; 29(1): 26-38. 